\title{
Çocuk nöroloji polikliniğine başvuran migren tanılı hastaların retrospektif özelliklerinin incelenmesi
}

\author{
Investigation of patients with migraine admitted to pediatric neurology outpatient \\ clinic: a retrospective study
}

Hilal Aydın, İbrahim Hakan Bucak

Özet

Amaç: Çocuk nöroloji pratiğinde migren oldukça sık rastlanılmaktadır. Migren tanısı hasta hikayesi ve ayrıntılı nörolojik muayane ile konulur. Bu çalışmada yeni kurulan bir çocuk nöroloji polikliniğinde migren tanısı konulan olgularımızın klinik ve demografik özelliklerini retrospektif olarak sunmayı hedefledik.

Gereç ve yöntem: Üçüncü basamak bir hastanenin (Adıyaman Üniversitesi Tıp Fakültesi) çocuk nöroloji polikliniğine 01 Ekim 2017-30 Nisan 2019 tarihleri arasında baş ağrısı şikayeti ile başvuran ve pediatrik hastalarda "Migren Tipi Baş Ağrısı Tanı Ölçütleri (ICHD-3 beta)" kriterleri temel alınarak migren tanısı konulan 55 hasta retrospektif olarak incelendi.

Bulgular: Olguların yaş ortalaması 12,25 $\pm 2,25$ (8-17) yıl idi. Hastaların 29'u (\%52,73) erkek ve 26'sı (\%47,27) kız idi. Kız olguların yaş ortalaması 13,15 $\pm 2,67$ (8-17) yıl ve erkek olguların yaş ortalaması 12,75 $\pm 1,57(9,16-16)$ yıl idi. Migren vakalarının 11-14 yaş grubunda erkek cinsiyette, 15-18 yaş grubunda kız cinsiyette daha fazla olduğu saptandı. Ataklarda ağrı süresi $80,19 \pm 24,29 \mathrm{dk}$ (30-120 dakika) olarak belirlenmiştir. Baş ağrısına 46 $(\% 83,64)$ hastada fotofobi ve fonofobi, $40(\% 72,74)$ hastada bulantı ve kusma eşlik ettiği saptandı. Olguların 30 'unda $(\% 54,54)$ ağrıyı tetikleyici etken olduğu izlendi. Eliminasyon konusunda bilgi verildikten sonra 19 $(\% 34,54)$ hastanın baş ağrısı sıklığı ve süresinde azaldığı görüldü. Profilaktik tedavi 35 hastaya başlandı ve en sık tercih edilen ilaç fluranizindi. Önleyici tedavi başlanılan hastaların hepsinde ağrı sıklığı ve süresinde azalma saptandı.

Sonuç: Migren tanısı konulan hastalara provakatif faktörler konusunda bilgilendirildi. Eliminasyon sonrası, hastaların baş ağrısı sıklık ve sayısının azaldığı görüldü.

Anahtar kelimeler: Çocuk, birincil baş ağrısı, migren, fluranizin.

Aydın H, Bucak İH. Çocuk nöroloji polikliniğine başvuran migren tanılı hastaların retrospektif özellikleri. Pam Tıp Derg 2021;14:330-336.

\begin{abstract}
Purpose: Migraine is common in pediatric neurology practice. The diagnosis of migraine is made based on a thorough anamnesis to be taken from the patient and detailed neurological examination. The aim of this study was to retrospectively present the clinical and demographic characteristics of patients diagnosed with migraine in a newly established pediatric neurology outpatient clinic.

Materials and methods: This study retrospectively analyzed the data of a total of 55 pediatric patients, who were admitted to Adıyaman University Faculty of Medicine pediatric neurology outpatient clinic between 1 October 2017 and 30 April 2019 with the complaint of headache and diagnosed with migraine based on the Diagnostic Criteria for Migraine Type Headache in pediatric patients published in the third edition of the International Classification of Headache Disorders (ICHD-3).

Results: The mean age of the patients was $12.25 \pm 2.25$ (8-17) years. Twenty-six (47.27\%) of the patients were female and $29(52.73 \%)$ were male. The mean age of the female and male patients was $13.15 \pm 2.67(8-17)$ years and $12.75 \pm 1.57(9.16-16)$ years, respectively. The prevalence of migraine was found to be higher in male patients aged 11-14 years and in females aged 15-18 years. The duration of pain in attacks was determined to be $80.19 \pm 24.29$ minutes (30-120 minutes). Headache was found to be accompanied by photophobia and phonophobia in $46(83.64 \%)$ patients and by nausea and vomiting in $40(72.74 \%)$ patients. The triggering factor was found to be present in 30 of the cases $(54.54 \%)$. After patients were informed about elimination, a decrease in the frequency and duration of headache was observed in 19 (34.54\%) patients. Prophylactic treatment was
\end{abstract}

Hilal Aydın, Dr. Öğr. Üye. Balıkesir Üniversitesi Tıp Fakültesi Çocuk Sağlığı ve Hastalıkları Anabilim Dalı, Çocuk Nöroloji Bölümü, Balıkesir, Türkiye, e-posta: drhilalaydin@gmail.com (https://orcid.org/0000-0002-2448-1270) (Sorumlu Yazar)

İbrahim Hakan Bucak, Doç. Dr. Adıyaman Üniversitesi Tıp Fakültesi, Çocuk Sağlığı ve Hastalıkları Anabilim Dalı, Adıyaman, Türkiye, e-posta: drhbucak@gmail.com (https://orcid.org/0000-0002-3074-6327) 
initiated in 35 patients and the most preferred drug was flunarizine. A decrease was observed in the frequency and duration of pain in all patients for whom preventive treatment was initiated.

Conclusion: Patients diagnosed with migraines were informed about provocative factors. The frequency and the number of headache was observed to decrease after elimination.

Key words: Child, primary headache, migraine, fluranizine.

Aydın H, Bucak IH. Investigation of patients with migraine admitted to pediatric neurology outpatient clinic: a retrospective study. Pam Med J 2021;14:330-336.

\section{Giriş}

Migren pediatrik populasyonda oldukça sık görülmektedir. Migren prevelansı ergenlik döneminde artmakta, 5 ila 10 yaş arası çocuklarda \%5, gençlerde \%15 oranında görülmektedir [1, 2]. Migren çocuk ve erken ergenlik döneminde kız ve erkeklerde eşit oranda görülürken, geç ergenlik döneminde kızlarda daha fazla izlendiği ve bu oranın erişkinlerle benzerlik gösterdiği belirtilmiştir [1]. Pediatrik hastalarda migren tanısı Migren Tipi Baş Ağrısı Tanı Ölçütleri (ICHD-3 beta) şunlardır [3];

A. En az beş atak $B$ ve $D$ tanı kriteri ölçütlerini karşılamalı

B. Baş ağrısı 2-72 saat sürmeli

C. Baş ağrısının özellikleri aşağıdakilerden en az ikisini kapsamalı

- Tek taraflı bazen bilateral, frontotemporal bölgede görülebilen

-Zonklayıcı vasıfta

- Şiddetli

- Fiziksel aktivite ile ağrıda artış gözlenmesi ağrı sırasında aktiviteden kaçınma

D. Baş ağrısı ile eş zamanlı aşağıdakilerden en az biri gözlenmeli

- Bulantı ve/veya kusma

- Fotofobi ve fonofobi

E. Altta yatan başka bir neden bulunmamalı

$\mathrm{Bu}$ çalışmamızda yeni kurulan bir çocuk nöroloji polikliniğinde migren tanısı konulan olgularımızın klinik ve demografik özelliklerini retrospektif olarak sunmayı hedefledik.

\section{Gereç ve yöntem}

Çalışma, üçüncü basamak bir hastanenin çocuk nöroloji polikliniğine 01.10.201730.04.2019 tarihleri arasında baş ağrısı şikayeti ile başvuran ve pediatrik hastalarda "Migren Tipi Baş Ağrısı Tanı Ölçütleri (ICHD-3 beta)" kriterleri temel alınarak migren tanısı konulan 55 hasta retrospektif olarak incelenmiştir. Olguların demografik özellikleri (yaş, cinsiyet), migren ile ilişkili klinik özellikleri 'baş ağrısının özellikleri, yakınma süresi, baş ağrısı sıklığı (haftalık atak sayısı), baş ağrısı süresi, lokalizasyonu (tek/çift tarafı), bulantı-kusma-fotofobifonofobi gibi eşlik eden bulgular, aura varlığı, aktiviteyle tetiklenme/artma öyküsü', özgeçmiş ve soygeçmiş öyküleri, koruyucu tedavi alıp almadıkları incelenmiştir.

Eşlik eden epilepsi/nöbet, mental retardasyon, serebral palsi gibi nörolojik bir hastalığı olan veya sistemik kronik bir hastalığı olan, baş ağrısına sebep olabilecek herhangi bir kronik hastalığı veya patolojisi olan (intrakranial tümorler, inflamatuar hastalıklar, kranial nevraljiler, yakın zamanda kafa travması), kronik günlük baş ağrısı, küme baş ağrısı, kronik/ epizodik migren saptanan veya ilaç kullanan hastalar çalışmaya dahil edilmedi.

İstatistiksel analiz SPSS (23.0, Chicago, IL, USA) programı kullanılarak yapıldı. Değişkenler ortalama \pm standart sapma, sayı (n) ve yüzde (\%) olarak gösterildi. Çalışma için, Adıyaman Üniversitesi Girişimsel Olmayan Klinik Araştırmalar Etik Kurulu'ndan onay alındı.

\section{Bulgular}

Çalışmaya 55 migren hastası dahil edildi. Olguların yaş ortalaması $12,25 \pm 2,25$ (8-17) yıl idi. Hastaların 26 'si $(\% 47,27)$ kız ve 29 'ü $(\% 52,73)$ erkek idi. Kız olguların yaş ortalaması $13,15 \pm 2,67$ (8-17) yıl ve erkek olguların yaş ortalaması $12,75 \pm 1,57(9,16-16)$ yıl idi. Migren 
başlama yaşı ortalama $11,6 \pm 2,46$ (5-17) yıl olarak tespit edildi. Erkeklerin migren başlama yaşı ortalama 11,95 $\pm 2,97$ (5-17) yıl, kızların

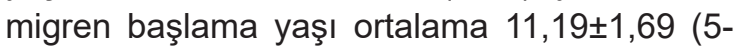
17) yıl idi. 7-10 yaş arası migren tanısı konulan $9(\% 16,36)$ olgu, $11-14$ yaş arası $33(\% 60)$ olgu, $15-18$ yaş arası $13(\% 23,64)$ olgu tespit edildi. $7-10$ yaş arası $5(\% 9,09) \mathrm{kız}$ olgu, $4(\% 7,27)$ erkek olgu, 11-14 yaş arası $21(\% 38,18)$ erkek olgu, $12(\% 21,82) \mathrm{kIz}$ olgu, 15-18 yaş arası $9(\% 16,37) \mathrm{kIz}$ olgu, $4(\% 7,27)$ erkek olgu saptandı. 11-14 yaş arasında erkek olguların, 15-18 yaş arasında kız olguların daha fazla olduğu saptandı. Tablo 1'de yaş aralıklarına göre cinsiyet dağılımı gösterilmiştir.

11 (\%20) olguda görsel, $3(\% 5,45)$ olguda duyusal aura olmak üzere toplam $14(\% 25,45)$ olguda baş ağrısı öncesinde aura bildirilmiştir. Baş ağrısı sıklığı $5(\% 9,09)$ hastada her gün, 37
(\%67,27) hastada haftada 2-6 kez, 4 (\%7,27) hastada haftada $1 \mathrm{kez}, 9(\% 16,37)$ hastada ayda 1-3 kez olarak belirtildi. Ataklarda ağrı süresi $80,19 \pm 24,29 \mathrm{dk}(30-120 \mathrm{dk})$ olarak belirlenmiştir ve ağrı süresi $90 \mathrm{dk}$ olanların sayısı çoğunluğu oluşturmaktaydı (n:37, \%67,27). Baş ağrısı karakteri sorgulandığında $26(\% 47,27)$ hastanın bilateral, $29(\% 52,73)$ hastanın unilateral tutulum, $19(\% 34,54)$ hastanın frontal bölgede, $21(\% 38,18)$ hastanın temporal bölgede ve 15 $(\% 27,28)$ hastada tüm kafayı saran özellikte olduğu belirlendi. Sekiz $(\% 14,55)$ hastada bulantı ve kusmanın eşlik etmediği, 40 $(\% 72,73)$ hastada bulantı ve kusma eşlik ettiği, $6(\% 10,90)$ hastada sadece bulantı, $1(\% 1,82)$ hastada sadece kusma eşlik ettiği görüldü. Kırk altı $(\% 83,64)$ hastada baş ağrısına fotofobi ve fonofobi eşlik ettiği, 7 (\%12,72) hastada fotofobi ve fonofobinin eşlik etmediği, $2(\% 3,64)$ hastada sadece fotofobinin eşlik ettiği saptandı.

Tablo 1. Olguların yaş aralıklarına göre cinsiyet dağılımı

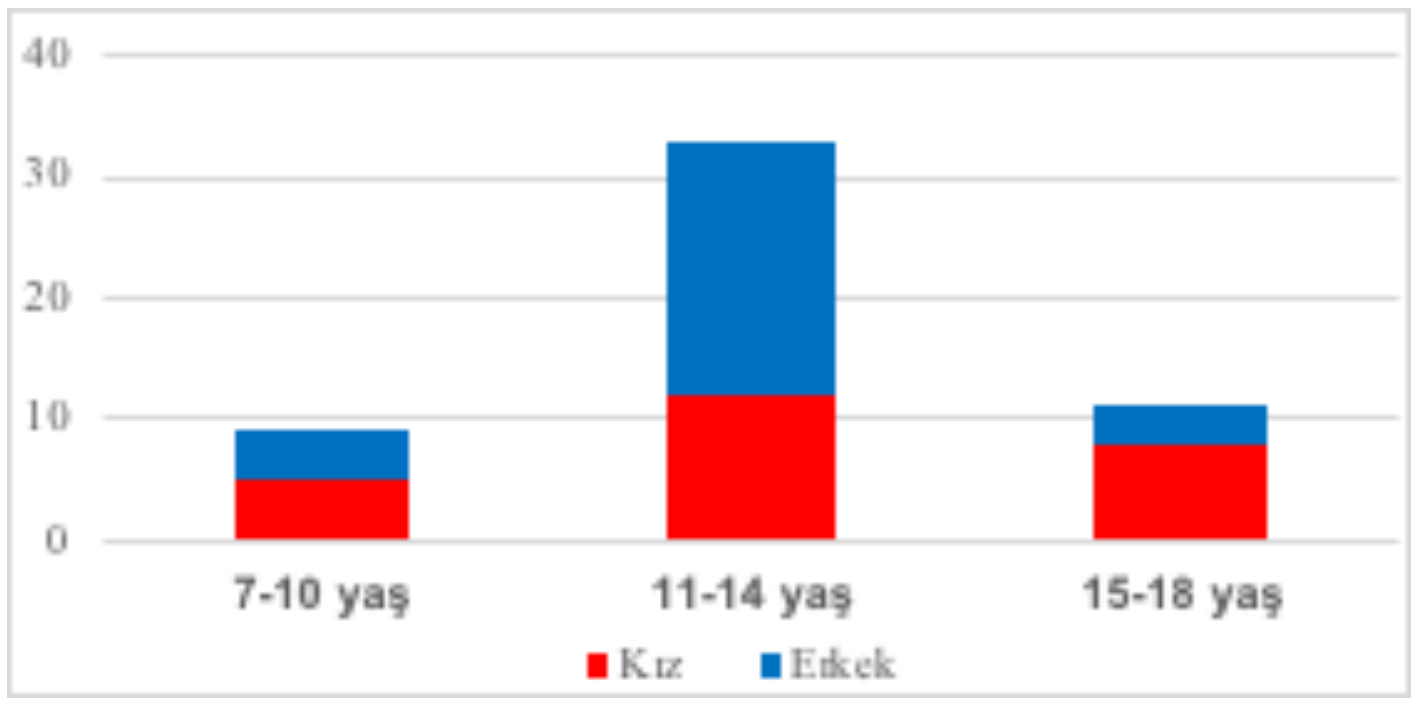

Hastaların 35'inde (\%63,63) ailede migren öyküsü saptandı. Olguların 30'unda (\%54,54) ağrıyı tetikleyici etken olduğu belirlendi. Tetikleyici etkenler arasında en sık gürültü ve ışık (n:26, \%47,27), en az (n:1, \%1,82) kalabalık oluşturmaktaydı. Beş $(\% 9,09)$ olgu vücut ağırlığına göre >97 persantil, $7(\% 12,72)$ olgu $<3$ persantil olarak tespit edildi.
Hastalara önleyici tedbirler konusunda bilgi verildikten sonra, 19 (\%34,54) hastanın baş ağrısı sıklığı ve süresinde azaldığı görüldü. $20(\% 36,36)$ olguya atak anında analjezik, 35 $(\% 63,64)$ olguya önleyici tedavi [30 (\%54,54) olguya fluranizin, $2(\% 3,64)$ olguya propranolol, $3(\% 5,46)$ olguya topiramat)] başlanıldı. Önleyici tedavi başlanılan hastaların hepsinde ağrı sıklığı ve süresinde azalma saptandı. Olgularımızın klinik ve demografik özellikleri Tablo 2'de sunuldu. 
Tablo 2. Olguların klinik ve demografik özellikleri

\begin{tabular}{|c|c|}
\hline Hasta Sayısı & 55 \\
\hline Yaş ortalaması, yıl; \pm SS & $12,25 \pm 2,25(8-17)$ \\
\hline \multirow[t]{2}{*}{ Cinsiyet (Erkek/Kız) } & Erkek n:29 (\%52,73) \\
\hline & KIz n:26 (\%47,27) \\
\hline \multicolumn{2}{|l|}{ Yaş dağılımı } \\
\hline $7-10$ yaş & $\mathrm{n}: 9(\% 16,36)$ \\
\hline $11-14$ yaş & $\mathrm{n}: 33(\% 60)$ \\
\hline $15-18$ yaş & n:13 (\%23,64) \\
\hline Baş ağrısı süresi & $80,19 \pm 24,29 \mathrm{dk}$ (30-120 dakika) \\
\hline \multicolumn{2}{|l|}{ Baş ağrısı atak sayısı } \\
\hline Her gün & $\mathrm{n}: 5(\% 9,09)$ \\
\hline 2-6 kez/hafta & n:37 $(\% 67,27)$ \\
\hline $1 \mathrm{kez} / \mathrm{hafta}$ & $\mathrm{n}: 4(\% 7,27)$ \\
\hline 1-3 kez/ay & $\mathrm{n}: 9(\% 16,37)$ \\
\hline Auralı migren (\%) & n:14 (\%25,45) \\
\hline Aurasız migren (\%) & n:41 (\%74,55) \\
\hline Tek taraflı (\%) & n:29 (\%52,73) \\
\hline Çift taraflı (\%) & n:26 (\%47,27) \\
\hline Bulantı-kusma (\%) & $\mathrm{n}: 40(\% 72,74)$ \\
\hline Sadece bulantı (\%) & $\mathrm{n}: 6(\% 10,90)$ \\
\hline Sadece kusma (\%) & $\mathrm{n}: 1(\% 1,82)$ \\
\hline Bulantı-kusma yok (\%) & $\mathrm{n}: 8(\% 14,54)$ \\
\hline Fotofobi - Fonofobi (\%) & n:46 $(\% 83,64)$ \\
\hline Fonofobi (\%) & n:0 (\%0) \\
\hline Fotofobi (\%) & $\mathrm{n}: 2(\% 3,64)$ \\
\hline Fotofobi-fonofobi yok (\%) & $\mathrm{n}: 7(\% 12,72)$ \\
\hline Ailede migren öyküsü (\%) & n: $35(\% 63,63)$ \\
\hline Ağrıyı tetikleyici etmenden etkilenen olgu sayısı (\%) & n:30 $(\% 54,54)$ \\
\hline $\begin{array}{l}\text { Eliminasyon sonrası baş ağrısı sıklığı ve sayısı azalan } \\
\text { olgu }\end{array}$ & n:19 $(\% 34,54)$ \\
\hline - Ataklar anında analjezik & $\mathrm{n}: 20(\% 36,36)$ \\
\hline • Önleyici tedavi & n:35 (\%63,64) \\
\hline - Fluranizin & n:30 (\%54,54) \\
\hline - Propranolol & $\mathrm{n}: 2(\% 3,64)$ \\
\hline Topiramat & $\mathrm{n}: 3(\% 5,46)$ \\
\hline
\end{tabular}




\section{Tartışma}

Migren çocuk ve ergenlerin yaklaşık \%10'unu etkilemektedir. Migren çocuk ve erken ergenlik döneminde, kız ve erkeklerde eşit oranda görülmektedir. Geç ergenlik döneminde ise kızlarda daha fazla izlendiği ve bu dönemde migren görülme sıklığının erişkinlerle aynı olduğu belirtilmiştir [1]. Literaturde Akyol ve ark.'nın [4] yaptığı çalışmada 9-15 yaş arası çocuklarda kız/erkek oranı: 1,5, Abu Arafeh ve Russel [5] çalışmasında 5-15 yaş arasında migreni olan olgularda kı/erkek oranı 1,4 olarak saptamışlardır. Bizim çalışmamızda literatürden farklı olarak erkek cinsiyet çoğunluğu oluşturmaydı. 15-18 yaş grubunda migren kız cinsiyette daha fazla izlenirken, yine literatürden farklı olarak 11-14 yaş grubunda migrenin erkek cinsiyette daha fazla görüldüğü saptandı. Bu durumun, 11-14 yaş grubunda hem hasta sayısının hem de erkek cinsiyetin en fazla görüldüğü yaş grubu olması nedeni ile anlaşılamadı.

Uluslararası Baş Ağrısı Sınıflandırma Komitesine göre migren; çocuklarda sıklıkla bilateral izlenirken, geç ergenlik ve erken yetişkin dönemde migrene bağlı baş ağrısı tek taraflı olma eğilimindedir [3]. Migrenli hastalar genellikle ses ve ışığa hassastırlar. Bulantı, fiziksel aktivite ile ağrının provake olması beklenmektedir. Bizim çalışmamızda baş ağrısı karakteri sorgulandığında; baş ağrısı çoğunlukla unilateral ve temporal bölgede, baş ağrısına fotofobi-fotofobi ve bulantı-kusma eşlik ettiği görüldü. Hershey ve ark. [6] 125 migren tanılı çocuk hastada ağrının yaklaşık \%83 oranında bilateral olduğunu, Akyol ve ark.'nın [4] yaptığı çalışmada ise migren baş ağrısının $\% 76,5$ oranında unilateral olduğu bildirilmiştir. Akyol ve ark. [4] migrenli hastalarda fotofobi ve fonofobi \%75,8, bulantı ve/veya kusma \%69,8 saptamışlardır. Bizim çalışmamızda baş ağrısına $40(\% 72,73)$ hastada bulantı ve kusma, $46(\% 83,64)$ hastada fotofobi ve fonofobi eşlik ettiği görülmüştür. Baş ağrısına eşlik eden semptomlar literatur bilgileri ile uyumlu olarak saptandı. Migren tanısı konulan olgularda baş ağrısı olduğu dönemlerde rutin etkinliklerden kaçınma ve okul devamsızlığı görüldüğü raporlanmıştır [7]. Hastalarımızı okul devamsızlığı açısından değerlendiremediğimiz için bu konuda veri sağlayamadık.

Migren ile ilgili auralı ve aurasız olmak üzere iki klinik sendrom belirtilmiştir [8]. Aurasız migren, auralı migrenden daha sık görülmektedir. Aura; geçici nörolojik semptomlar olarak tanımlanır, özellikle duyusal veya görsel semptomlar şeklinde migrenli hastaların \%10-15'inde ortaya çıkmaktadır [9]. Auralı migren tanılı, yaşları 5-17 arasında, 164 olgunun değerlendirildiği retrospektif bir kohortta, atak sırasında görsel semptomlar olguların \%93'ünde ve duyusal semptomlar olguların \%5,5'inde saptanmıştır [10]. Auralı migren görülme sıklığını Abu Arafeh ve Russel [5] \%26,4, Mavromichalis ve ark. [11] \%45,2 oranında bildirmişlerdir. Bizim çalışmamızda $\% 5,45$ olguda duyusal semptomlar saptanırken, \%20 olguda görsel semptomlar izlenmiştir. Auralı migren görülme sıklığı literatur ile uyumlu bulunurken, görsel semptomların az rastlanılması çalışmaya alınan hasta sayısının az olması ile ilişkilendirildi.

Çocukluk çağı migren tedavisi; önleyici ve atak tedavisi şeklindedir. Önleyici tedavide ilk basamak; yaşam tarzı değişikliği ve tetikleyici etmenlerin saptanıp eliminasyonunun sağlanmasıdır. Önleyici tedavide düzenli fiziksel aktivite, gevşeme teknikleri, uyku hijyeni, stress yöntemi ve kafein alımının azaltımı gibi bazı yaklaşım yöntemleri mevcuttur [12]. Hastalarımızın 30'unda (\%54,54) ağrıyı tetikleyici etmenler saptanmış ve eliminasyon sonrası $19(\% 34,54)$ olgunun baş ağrısı sıklığı ve sayısının azaldığı görüldü. Haftada iki veya daha fazla atak geçiren hastalarda koruyucu tedavilerin gerekli olduğu vurgulanmaktadır [13]. Pediatrik migren hastalarında koruyucu tedavinin seçilmesinde standartize edilmiş bir rehber bulunmamaktadır. Koruyucu tedaviler arasında; antidepresanlar (amitriptilin), triptanlar, antiepileptik ilaçlar (topiramat, valproik asit, levetirasetam), kalsiyum kanal blokeri, nutrisyonel destek ürünleri (B2, Mg, koenzim $\mathrm{Q}$ ) kullanılan ilaçlardır. Fluranizin önleyici migren tedavisinde sık kullanılan ilaçlardan biridir [14]. 
Bizim olgularımızda da fluranizin başlanılan hasta sayısı $30(\% 54,54)$ idi. Fluranizin tedavisi başlanan hastaların tamamında baş ağrısı sıklık ve sayısında azalma olduğu belirlendi. Fluranizin önleyici migren tedavisinde kullanılması gerektiği sonucuna varıldı.

$\mathrm{Bu}$ araştırmanın retrospektif karakterde olması, okula devamsızlık konusunda sorgulamanın yeterli yapılamaması ve hasta sayısının azolması çalışmamızdaki kısıtlılıklar olarak değerlendiriyoruz.

Sonuç olarak, migren tanısı konulan hastalara gereksiz laboratuvar tetkiklerinden kaçınılarak baş ağrısına sebep olabilecek provakatif ve kötüleştiren faktörler konusunda uyarıldı. Eliminasyon sonrası hastaların baş ağrısı sıklık ve sayısının azaldığı görüldü. Profilaktik tedavi gerektiren olgularda en sık kullandığımız ilaç fluranizin olup; ilaçla ilgili herhangi bir yan etkiye rastlanılmadı. Daha fazla sayıda migren tanılı olguların klinik ve demografik özelliklerin paylaşıldığı prospektif çalışmalara ihtiyaç duyulmaktadır.

Çıkar ilişkisi: Yazarlar çıkar ilişkisi olmadığını beyan eder.

\section{Kaynaklar}

1. Abu Arafeh I, Razak S, Sivaraman B, Graham C. Prevalence of headache and migraine in children and adolescents: a systematic review of population- based studies. Dev Med Child Neurol 2010;52:1088-1097. https://doi.org/10.1111/j.1469-8749.2010.03793.x

2. Victor TW, Hu X, Campbell JC, Buse DC, Lipton RB. Migraine prevalence by age and sex in the United States: a life-span study. Cephalalgia 2010;30:10651072. https://doi.org/10.1177/0333102409355601

3. Headache Classification Committee of the International Headache Society (IHS) The International Classification of Headache Disorders, 3rd edition. Cephalalgia 2018;38:1-211. https://doi. org/10.1177/0333102417738202

4. Akyol A, Kiylioglu N, Aydin I, et al. Epidemiology and clinical characteristics of migraine among school children in the Menderes region. Cephalalgia 2007;27:781-787. https://doi.org/10.1111/j.14682982.2007.01343.x
5. Abu Arafeh I, Russel G. Prevalence of headache and migraine in school children. BMJ 1994;309:765-769. https://doi.org/10.1136/bmj.309.6957.765

6. Hershey $A D$, Winner $P$, Kabbouche MA, et al. Use of the ICHD-II criteria in the diagnosis of pediatric migraine. Headache 2005;45:1288-1297. https://doi. org/10.1111/j.1526-4610.2005.00260.x

7. Lewis DW. Pediatric migraine. Neurol Clin 2009;27:481501. https://doi.org/10.1016/j.ncl.2008.11.003

8. Kelly M, Strelzik J, Langdon R, DiSabella M. Pediatric headache: overview. Curr Opin Pediatr 2018;30:748754. https://doi.org/10.1097/MOP.0000000000000688

9. Spiri D, Rinaldi VE, Titomanlio L. Pediatric migraine and episodic syndromes that may be associated with migraine. Ital J Pediatr 2014:40;92. https://doi. org/10.1186/s13052-014-0092-4

10. Balestri $M$, Papetti $L$, Maiorani $D$, et al. Features of aura in paediatric migraine diagnosed using the ICHD 3 beta criteria. Cephalalgia 2018;38:1742-1747. https://doi. org/10.1177/0333102417748571

11. Mavromichalis I, Anagnostopoulos D, Metaxas $\mathrm{N}$, Papanastassiou E. Prevalence of migraine in school children and some clinical comparisons between migraine with and without aura. Headache 1999;39:728-736. https://doi.org/10.1046/j.15264610.1999.3910728.x

12. Torriero R, Capuano A, Mariani R, et al. Diagnosis of primary headache in children younger than 6 years: a clinical challenge. Cephalalgia 2017;37:947-954. https://doi.org/10.1177/0333102416660533

13. Kroon Van Diest AM, Powers SW. Cognitive behavioral therapy for pediatric headache and migraine: why to prescribe and what new research is critical for advancing integrated biobehavioral care. Headache 2019;59:289-297. https://doi.org/10.1111/head.13438

14. Dooley JM. The evaluation and management of pediatric headaches. Pediatr Child Health 2009;14:2430. https://doi.org/10.1093/pch/14.1.24

Etik kurul onayı: Bu çalışma için, Adıyaman Üniversitesi Girişimsel Olmayan Klinik Araştırmalar Etik Kurulu'ndan 05.10.2020 tarih ve 2020/9-28 sayı ile onay alınmıştır. 


\section{Yazarların makaleye olan katkıları}

H.A. çalışmanın ana fikrini ve hipotezini kurgulamıştır. H.A. ve İ.H.B teoriyi geliştirmiş ve materyel metod bölümünü düzenlemişlerdir. Sonuçlar kısmındaki verilerin değerlendirmesini H.A. yapmıştır. Makalenin tartışma bölümü H.A. ve İ.H.B tarafından yazılmış, I.H.B. gözden geçirip gerekli düzeltmeleri yapmış ve onaylamıştır. Ayrıca tüm yazarlar çalışmanın tamamını tartışmış ve son halini onaylamıştır. 